\title{
A complex translocation $(3 ; 17 ; 15)$ in acute promyelocytic leukemia confirmed by fluorescence in situ hybridization
}

\author{
YANMING WANG ${ }^{1,2}$, JUNJIE MA $^{2}$, XINGUANG LIU ${ }^{1}$, RIMING LIU $^{2}$, LINGLING XU $^{2}$, \\ LI WANG $^{2}$, JIANNONG CEN ${ }^{3}$ and XIAOXIA CHU ${ }^{2}$ \\ ${ }^{1}$ Department of Hematology, Qilu Hospital of Shandong University, Jinan, Shandong 250012; ${ }^{2}$ Department of Hematology, \\ Yantai Yuhuangding Hospital, Yantai, Shandong 264000; ${ }^{3}$ Jiangsu Institute of Hematology, \\ Collaborative Innovation Center of Hematology, Key laboratory of Thrombosis and Hemostasis of Ministry of Health, \\ The First Affiliated Hospital of Soochow University, Suzhou, Jiangsu 215006, P.R. China
}

Received April 18, 2015; Accepted July 28, 2016

DOI: $10.3892 / \mathrm{ol} .2016 .5280$

\begin{abstract}
Acute promyelocytic leukemia (APL) is typified by $\mathrm{t}(15 ; 17)(\mathrm{q} 22 ; \mathrm{q} 21)$, generating the promyelocytic leukemia (PML) gene at 15q22 with the retinoic acid $\alpha$-receptor (RARA) gene at 17q21. The PML-RARA fusion gene is believed to play a vital role in leukemogenesis. A sizeable minority of patients with complex variants of APL have been reported. The present study reports the case of a 33-year-old male with APL carrying a potential complex translocation. The initial symptom was bleeding gums. Chromosomal analysis of the bone marrow cells revealed an atypical $17 \mathrm{q}$ aberration. Fluorescence in situ hybridization further indicated that $92 \%$ of analyzed cells were positive for the PML-RARA fusion gene. The patient experienced complete remission following treatment with arsenic trioxide and chemotherapy. The atypical translocations in acute promyelocytic leukemia require further investigation.
\end{abstract}

\section{Introduction}

Acute promyelocytic leukemia (APL), a distinct subtype of acute myeloid leukemia, is defined by a specific balanced translocation, $\mathrm{t}(15 ; 17)$, leading to the fusion of the promyelocytic leukemia (PML) and retinoic acid receptor- $\alpha$ (RARA) genes $(1,2)$. The PML-RARA gene is supposed to play a vital role in the pathophysiological process of APL (3), and patients with the fusion gene could benefit from treatment with all-trans retinoic acid (ATRA) and $\mathrm{AS}_{2} \mathrm{O}_{3}$.

As supported by fluorescence in situ hybridization (FISH) assessment, complex variant translocations of 15;17 have been increasingly reported in APL, while the majority of complex

Correspondence to: Dr Xiaoxia Chu, Department of Hematology, Yantai Yuhuangding Hospital, 20 Yuhuangding East Road, Yantai, Shandong 264000, P.R. China

E-mail: lucychu66@163.com

Key words: complex translocation, $\mathrm{t}(3,15,17)$, acute promyelocytic leukemia variants of APL have revealed three-way translocations $(4,5)$. The current study presents the fifth three-way translocation involving chromosomes $3 ; 17 ; 15$ (6-8), which may be the second breakpoint involving the long arm of chromosome 3 reported thus far. Written informed consent was obtained from the patient for the publication of this study.

\section{Case report}

A 33-year-old male with no significant previous medical history was admitted to Yantai Yuhuangding Hospital (Yantai, Shandong, China) in July 2014 due to bleeding gums. A peripheral blood examination showed the following: Hemoglobin, $10.2 \mathrm{~g} / \mathrm{dl}$ (normal, 13.0-17.5 g/dl); white blood cell count, $2.14 \times 10^{9} / 1$ (normal, 3.5-9.5 $\times 10^{9} / 1$ ), with $46 \%$ atypical promyelocytes packed with numerous azurophilic

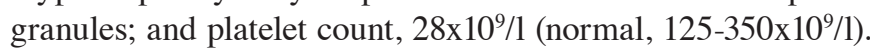
Coagulation tests revealed a prothrombin time of $19.4 \mathrm{sec}$ (normal, $15 \mathrm{sec}$ ), an activated partial thromboplastin time of $41.8 \mathrm{sec}$ (normal, $40 \mathrm{sec}$ ) and a fibrinogen level of $67 \mathrm{mg} / \mathrm{dl}$. Bone marrow was markedly hypercellular, with $84.5 \%$ atypical promyelocytes. The promyelocytes were stained by allophycocyanin (APC)-conjugated cluster of differentiation (CD)33 (dilution, 1:2; catalog no. 340474), phycoerythrin (PE)-conjugated CD123 (dilution, 1:10; catalog no. 340545), APC-conjugated CD38 (dilution, 1:2; catalog no. 345807), PE-conjugated CD13 (dilution, 1:5; catalog no. 347837) and PerCP-conjugated CD45 (dilution, 1:5; catalog no. 347464). All of the antibodies were monoclonal, composed of mouse immunoglobulin G1 heavy chains and $\kappa$ light chains, diluted with phosphate-buffered saline and purchased from BD Biosciences (Franklin Lakes, NJ, USA). The immunophenotype was $\mathrm{CD}_{3}{ }^{+}, \mathrm{CD}_{123}{ }^{+}, \mathrm{CD}_{117^{+}}, \mathrm{CD} 38^{+}$and $\mathrm{CD} 13^{+}$. The PML-RARA (L-form) rearrangement was confirmed by reverse transcription polymerase chain reaction (RT-PCR), and a diagnosis of APL [M3 in the French-American-British classification (9)] accompanying disseminated intravascular coagulation (DIC) was formed. Due to ATRA (20 mg/m²/day) intolerance, the patient started induction therapy with arsenic trioxide alone at a daily dose of $10 \mathrm{mg}$ for 35 days, to induce remission through PML/RARA degradation, and cryoprecipitate transfusion to 


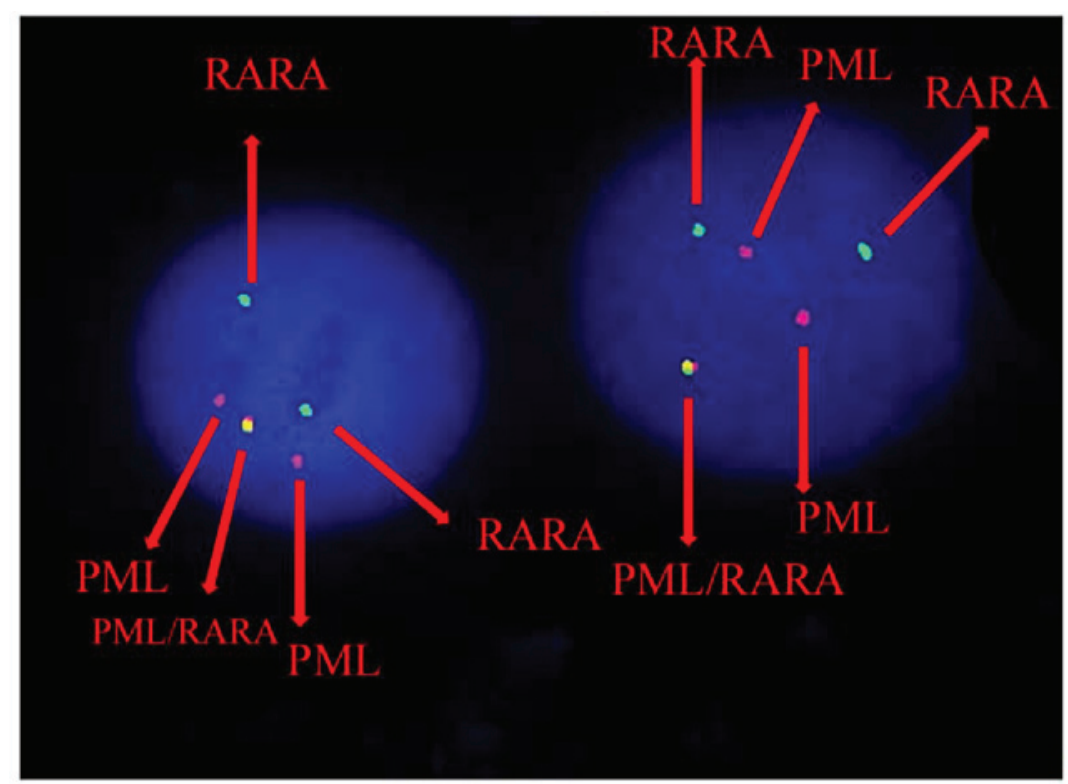

Figure 1. Fluorescence in situ hybridization analysis. Interphase cells demonstrating one PML/RARA fusion signal, two pink signals (PML), and two green signals (RARA), constistent with the karyogram $\operatorname{der}(3) \mathrm{t}(3 ; 17 ; 15)(\mathrm{q} 25 ; \mathrm{q} 21) ; \mathrm{q} 24), \operatorname{der}(15) \mathrm{t}(3 ; 17 ; 15), \operatorname{der}(17) \operatorname{der}(17)(\mathrm{q} 11 \mathrm{q} 12)$.

control the DIC (accumulated dose, 83 units). At 15 days after therapy initiation, the atypical promyelocytes started to differentiate. However, 27 days after therapy, the white blood cells reached a level of $144 \times 10^{9} / 1$ with no evidence of APL differentiation syndrome. Coinciding with this, symptoms of high cerebrospinal fluid pressure emerged. The patient subsequently received daunorubicin (20 $\mathrm{mg}$ for 3 days) and dexamethasone (10 mg for 3 days) treatment, as well as intrathecal methotrexate (12 mg), following which the white blood cell counts gradually decreased to normal. Molecular remission was achieved 10 days after the administration of the chemotherapy. The treatment was continued with 3 courses of medial-dose cytosine arabinoside. The patient currently remains in complete remission.

Karyotypic analysis and FISH. Cytogenetic analysis was performed on Giemsa-banded chromosome preparations. The karyotype was presented according to the 2005 International System for Human Cytogenetic Nomenclature (10). As the metaphases from abnormal cells were often of poor quality and resolution, it was difficult to cytogenetically identify the characteristic PML/RARA fusion gene. FISH was performed using the Vysis dual-color, dual-fusion probe (Abbott Molecular, Des Plaines, IL, USA) following the manufacturer's instructions. Fluorescent signals were visualized and images were captured using a fluorescence microscope. The FISH analysis revealed the $46, \mathrm{XY}, \operatorname{der}(3) \mathrm{t}(3 ; 17 ; 15)(\mathrm{q} 25 ; \mathrm{q} 21 ; \mathrm{q} 24)$, $\operatorname{der}(15) \mathrm{t}(3 ; 17 ; 15), \operatorname{der}(17) \operatorname{der}(17)(q 11 q 12)$ karyotype (Fig. 1).

RT-PCR analysis. Total RNA was extracted from mononuclear cells in a bone marrow sample obtained from the patient using TRIzol reagent (Gibco; Thermo Fisher Scientific, Inc.), and reversed transcription was performed. PCR for the PML-RARA fusion gene was performed as previously described (6). An initial denaturation at $94^{\circ} \mathrm{C}$ for $5 \mathrm{~min}$ was followed by 40 cycles at $94^{\circ} \mathrm{C}$ for $15 \mathrm{sec}$ and $60^{\circ} \mathrm{C}$ for $60 \mathrm{sec}$. The sequences of the PCR primers were as follows: PML-RARA forward,
5'-CCGTCATAGGAAGTGAGGTCT-3' and reverse, 5'-GGC TGGGCACTATCTCTTCA-3'; and GAPDH forward, 5'-TGG AGATAACACTCTAAGCATAACTAAAGGT-3' and reverse, 5'-TGGAGATAACACTCTAAGCATAACTAAAGGT-3'. The results demonstrated that only the L-type chimeric transcription was expressed, while the RARA/PML was not expressed.

\section{Discussion}

To date, $>35$ cases with three-way complex translocations have been reported (6-8,11-30). Among these translocations, 9 recurrent breakpoints have been identified, including $2 \mathrm{q} 21(5,14,26)$, $19 \mathrm{p} 13$ (5,24), 3p21 (7,8), 4q21 (13,15), 11q13 (18,21), $1 \mathrm{p} 36(16,19,22), 20 \mathrm{p} 13(23,31), 6 \mathrm{p} 21$ (27) and Xq13 (11,25). As a supplement, the present study reported another case of an APL patient harboring a three-way translocation involving chromosomes $3 ; 17 ; 15$. This case provided a similar survival outcome of this complex translocation compared with the previous 4 cases $(6,8)$.

According to FISH analysis, the complex translocation can be assessed as follows: $15 \mathrm{q} 24$-qter translocated to $3 \mathrm{q} 25$; a small piece of chromosome 17 (17q11-q22) to 15q24; and 3q25-qter connected to $17 \mathrm{q} 22$ that has been located in $\operatorname{der}(15)(\mathrm{q} 24)$.

To date, 4 cases of three-way translocation regarding $t(3 ; 17 ; 15)$ have been reported $(6,8)$. However, the breakpoint in the present case occurred in a novel area of the long arm of chromosome 3 . The previous 3 cases harboring 3;17;15, reported in 2009, 1980 and 1994 (6-8) reported survival times of 6 days, 33 months and 14 months, respectively. In the present study, the patient presented with the typical morphological and clinical features of APL, and exhibited a good response to (arsenic trioxide) and chemotherapy treatment, as observed in typical APL. Comigrating RARA/PML rearrangements were present in 2 cases from previous reports (8), which differed from the present case. On the basis of RT-PCR analysis, there were only PML-RARA fusion transcripts and the RARA/PML fusion 
gene was not expressed in this case. This was inconsistent with the opinion that the majority of cases of APL lacking the $t(15 ; 17)$ are still associated with the formation of the RARA/PML fusion gene (27).

The poor prognosis of the previously reported 3 cases with the three-way $\mathrm{t}(3 ; 17 ; 15)$ appears to be associated with early mortality, which may due to the absence of targeted therapy and the comigrating RARA/PML rearrangements. The inference is that the involvement of the $3 \mathrm{q} 25$ region has no clear effect on disease outcome, further supporting the aforementioned notions. It remains unclear if the aberration can affect clinical consequences. A close clinical follow-up will be important in the present patient and in other cases of APL with a three-way $\mathrm{t}(3 ; 17 ; 15)$.

\section{References}

1. de Thé H, Chomienne C, Lanotte M, Degos L and Dejean A: The $\mathrm{t}(15 ; 17)$ translocation of acute promyelocytic leukaemia fuses the retinoic acid receptor alpha gene to a novel transcribed locus. Nature 347: 558-561, 1990.

2. de Thé H, Lavau C, Marchio A, Chomienne C, Degos L and Dejean A: The PML-RAR alpha fusion mRNA generated by the $t(15 ; 17)$ translocation in acute promyelocytic leukemia encodes a functionally altered RAR. Cell 66: 675-684, 1991.

3. Wang ZY and Chen Z: Acute promyelocytic leukemia: From highly fatal to highly curable. Blood 111: 2505-2515, 2008.

4. Liu S, Li Q, Pang W, Bo L, Qin S, Liu X, Teng Q, Qian L and Wang J: A new complex variant $\mathrm{t}(4 ; 15 ; 17)$ in acute promyelocytic leukemia: Fluorescence in situ hybridization confirmation and literature review. Cancer Genet Cytogenet 130: 33-37, 2001.

5. Brunel V, Lafage-Pochitaloff M, Alcalay M, Pelicci PG and Birg F: Variant and masked translocations in acute promyelocytic leukemia. Leuk Lymphoma 22: 221-228, 1996.

6. Freeman CE, Mercer DD, Ye Y, Van Brunt J III and Li MM: Cytogenetic and molecular characterization of complex three-way translocations in acute promyelocytic leukemia. Beijing Da Xue Xue Bao 41: 477-479, 2009.

7. Bernstein R, Mendelow B, Pinto MR, Morcom G and Bezwoda W: Complex translocations involving chromosomes 15 and 17 in acute promyelocytic leukaemia. Br J Haematol 46: 311-314, 1980.

8. McKinney CD, Golden WL, Gemma NW, Swerdlow SH and Williams ME: RARA and PML gene rearrangements in acute promyelocytic leukemia with complex translocations and atypical features. Genes Chromosomes Cancer 9: 49-56, 1994.

9. Bennett JM, Catovsky D, Daniel MT, Flandrin G, Galton DAG, Gralnick HT and Sultan C: Proposal for the classification of the acute leukemias French-American-British (FAB) co-operative group. Br J Haematol 33: 451-458, 1976.

10. Shaffer LG and Tommerup N (eds): ISCN 2005: An International System For Human Cytogenetic Nomenclature. S. Karger, Basel, 2005.

11. Callen DF DB, Sage RE and Ford JH: A complex translocation in acute promyelocytic leukemia. Cancer Genet Cytogenet 16: 45-48, 1985.

12. Misawa S, Lee E, Schiffer CA, Liu Z and Testa JR: Association of the translocation $(15 ; 17)$ with malignant proliferation of promyelocytes in acute leukemia and chronic myelogenous leukemia at blastic crisis. Blood 67: 270-274, 1986.

13. Berger R, Flandrin G, Bernheim A, Le Coniat M, Vecchione D, Pacot A, Derré J, Daniel MT, Valensi F, Sigaux F, et al: Cytogenetic studies on 519 consecutive de novo acute nonlymphocytic leukemias. Cancer Genet Cytogenet 29: 9-21, 1987.

14. Bjerrum OW, Philip P, Pressler T and Tygstrup I: Acute promyelocytic leukemia with $\mathrm{t}(15 ; 17)$ and $\mathrm{t}(2 ; 17 ; 15)$. Cancer Genet Cytogenet 28: 107-111, 1987.

15. Huret JL, Couet D, Guilhot F, Brizard A and Tanzer J: A two-step $\mathrm{t}(4 ; \operatorname{der}(15)) \mathrm{t}(15 ; 17)$ complex translocation in an acute promyelocytic leukaemia and review of the literature. Leuk Res 11: 761-765, 1987.
16. Osella $\mathrm{P}$, Wyandt $\mathrm{H}$, Vosburgh $\mathrm{E}$ and Milunsky A: Report of a variant $\mathrm{t}(1 ; 15 ; 17)(\mathrm{p} 36 ; \mathrm{q} 22 ; \mathrm{q} 21.1)$ in a patient with acute promyelocytic leukemia. Cancer Genet Cytogenet 57: 201-207, 1991.

17. Ogawa S, Mitani K, Sato Y, Sugimoto K, Toyoshima H, Mano H, Takaku F, Yazaki Y and Hirai H: Detection of the $\mathrm{PML} / \mathrm{RAR}$ alpha fusion gene in acute promyelocytic leukemia with a complex translocation involving chromosomes 15, 17 and 18. Cancer Genet Cytogenet 69: 113-117, 1993.

18. Chen Z, Morgan R, Stone JF and Sandberg AA: Identification of complex $\mathrm{t}(15 ; 17)$ in APL by FISH. Cancer Genet Cytogenet 72 : 73-74, 1994.

19. Park JP and Fairweather RB: Complex $t(1 ; 15 ; 17)$ in acute promyelocytic leukemia with duplication of RAR alpha and PML sequences. Cancer Genet Cytogenet 89: 52-56, 1996.

20. Calabrese G, Min T, Stuppia L, Powles R, Swansbury JG, Morizio E, Peila R, Donti E, Fioritoni G and Palka G: Complex chromosome translocations of standard $\mathrm{t}(8 ; 21)$ and $\mathrm{t}(15 ; 17)$ arise from a two-step mechanism as evidenced by fluorescence in situ hybridization analysis. Cancer Genet Cytogenet 91: 40-45, 1996.

21. Casula L, Archidiacono N, Grazia Pau M, Addis M, Mura R, Galanello R, Biddau P, Cao A and Nucaro A: Cytogenetic and molecular characterization of a variant translocation associated with acute promyelocytic leukemia and involving chromosomes 11, 15 and 17. Leukemia 10: 1655-1657, 1996.

22. Galieni P, Marotta G, Vessichelli F, Diverio D, Minoletti F, Bucalossi A, Lo Coco F and Lauria F: Variant $t(1 ; 15 ; 17)$ (q23;q22;q23) in a case of acute promyelocytic leukemia. Leukemia 10: 1658-1661, 1996.

23. Yamamoto $K$, Hamaguchi $H$, Nagata $K$, Kobayashi $\mathbf{M}$, Takashima T and Taniwaki M: A new complex translocation $(15 ; 20 ; 17)(q 22 ; p 13 ; q 21)$ in acute promyelocytic leukemia. Cancer Genet Cytogenet 101: 89-94, 1998

24. Saitoh K, Miura I, Kobayashi Y, Kume M, Utsumi S, Takahashi N, Hatano Y, Nimura T, Hashimoto K, Takahashi S and Miura AB: A new variant translocation of $\mathrm{t}(15 ; 17)$ in a patient with acute promyelocytic leukemia (M3): t(15;19;17)(q22;p13;q12). Cancer Genet Cytogenet 102: 15-18, 1998.

25. Wan TS, Chim CS, So CK, Chan LC and Ma SK: Complex variant 15;17 translocations in acute promyelocytic leukemia. A case report and review of three-way translocations. Cancer Genet Cytogenet 111: 139-143, 1999.

26. Fujishima M, Takahashi N, Miura I, Kobayashi Y, Kume M, Nishinari T and Miura AB: A PML/RARA chimeric gene on chromosome 2 in a patient with acute promyelocytic leukemia (M3) associated with a new variant translocation: $t(2 ; 15 ; 17)$ (q21;q22;q21). Cancer Genet Cytogenet 120: 80-82, 2000.

27. Grimwade D, Biondi A, Mozziconacci MJ, Hagemeijer A, Berger R, Neat M, Howe K, Dastugue N, Jansen J, Radford-Weiss I, et al: Characterization of acute promyelocytic leukemia cases lacking the classic $\mathrm{t}(15 ; 17)$ : Results of the European Working Party. Groupe Français de Cy togénétique Hématologique, Groupe de Français d'Hematologie Cellulaire, UK Cancer Cytogenetics Group and BIOMED 1 European Community-Concerted Action 'Molecular Cytogenetic Diagnosis in Haematological Malignancies'. Blood 96: 1297-1308, 2000.

28. Xu L, Zhao WL, Xiong SM, Su XY, Zhao M, Wang C, Gao YR, Niu C, Cao Q, Gu BW, et al: Molecular cytogenetic characterization and clinical relevance of additional, complex and/or variant chromosome abnormalities in acute promyelocytic leukemia. Leukemia 15: 1359-1368, 2001.

29. Tirado CA, Golembiewski-Ruiz V, Horvatinovich J, Moore JO, Buckley PJ, Stenzel TT and Goodman BK: Cytogenetic and molecular analysis of an unusual case of acute promyelocytic leukemia with a $\mathrm{t}(15 ; 17 ; 17)(\mathrm{q} 22 ; \mathrm{q} 23 ; \mathrm{q} 21)$. Cancer Genet Cytogenet 145: 31-37, 2003.

30. Eclache V, Viguie F, Frocrain C, Cassinat B, Chomienne C, Cymbalista $F$ and Fenaux P: A new variant $t(6 ; 15 ; 17)$ (q25;q22;q21) in acute promyelocytic leukemia: Fluorescence in situ hybridization confirmation. Cancer Genet Cytogenet 159: 69-73, 2005.

31. Zaccaria A, Testoni M, Martinelli G, Pelliconi S, Buzzi M, Farbegoli P, Naldi S, Salvucci M and Tura S: Four-chromosomes complex translocations in acute promyelocytic leukemia: Description of two cases. Eur J Haematol 52: 129-133, 1994. 